\title{
A Rare Cause of Epistaxis, Hemoptysis and Anemia: Leech in the Nasopharynx
}

\author{
Ismail Iynen ${ }^{\mathrm{a}}$, Ozgur Sogut ${ }^{\mathrm{b}, \mathrm{c}}$, Imran San ${ }^{\mathrm{a}}$, Ferhat Bozkus ${ }^{\mathrm{a}}$, Mehmet T. Gokdemir ${ }^{\mathrm{b}}$
}

\begin{abstract}
Leeches are blood-sucking endoparasites that can be seen in different colors and sizes. Leech infestation is endemic in tropical regions like Mediterranean countries, Africa and Asia. Leeches enter the human body when the polluted water is drunk, and they localize in the mucosa of the oropharynx, nasopharynx, tonsils, esophagus or nose but rarely in larynx. Depending on its localisation in the body, the leech which attaches firmly on the mucosa secretes an anticoagulant substance called hirudin and may cause different clinical symptoms such as epistaxis, hemoptysis or hematemesis. A dark colored and moving foreign body in nasopharynx was observed in the endoscopic examination of three cases of 12 to 70 years of age who were applied to our emergency department with complaints of epistaxis, nasal obstruction and hemoptysis lasting for about a month. All three cases were from rural areas and used well water as drinking water. They were treated by immediate removal of the foreign body using forceps, and it was detected to be a species of leech. Following this procedure, all three cases recovered uneventfully. Although leeches are rarely observed in the respiratory system, it may occasionally cause life-threatening complications if it is not accurately diagnosed. Therefore, leech infestation should be considered as a cause of unexplained hemoptysis, epistaxis or anemia in leech-endemic areas. A definitive diagnosis can be made by endoscopic assessment.
\end{abstract}

Keywords: Leech infestation; Epistaxis; Hemoptysis; Anemia; Nasopharynx

\footnotetext{
Manuscript accepted for publication August 2, 2010

${ }^{a}$ Department of Otolaryngology, Head and Neck Surgery, Harran University, Faculty of Medicine Sanliurfa, Turkey

${ }^{b}$ Department of Emergency Medicine, Harran University, Faculty of Medicine, Sanliurfa, Turkey

${ }^{\mathrm{c} C}$ Corresponding author: Department of Emergency Medicine, Harran University, 63300 Sanliurfa, Turkey. Email: drosogut@harran.edu.tr

doi:10.4021/jmc41e
}

\section{Introduction}

Leeches are blood-sucking endoparasites that can be seen in different colors and sizes. Leech infestations occur more commonly in tropical regions like Mediterranean countries, Africa and Asia [1]. In Turkey, leech infestations are seen especially in rural regions where natural spring waters are used without proper treatment [2]. When water that includes young leeches are drunk without necessary caution, leeches enter through the mouth and attach themselves on the upper respiratory system or digestive system mucosa. These locations are mostly the nose, nasopharynx, oropharynx, tonsils, esophagus and rarely larynx mucosa [3, 4]. Depending on its localization in the body, the leech which attaches firmly on the mucosa secretes an anticoagulant substance called hirudin and may cause different clinical symptoms such as epistaxis, hemoptysis or hematemesis [5].

In this study, we report three cases presented with complaints of epistaxis, hemoptysis and anemia due to leeches in the light of existing literature.

\section{Case Report}

\section{Case 1}

In August 2008, our Otolaryngology outpatient clinic was consulted when a 57-year-old male did not show any progress despite the 7-day antibiotic treatment in the Internal Diseases Clinic where he had applied with about three weeks of hemoptysis complaint. No significant characteristic was detected in the personal and family history of the patient. He did not experience respiratory distress and hoarseness. A dark colored moving foreign body was detected in the nasopharynx of the patient during endoscopic examination. No abnormalities were found in the radiological, hematological and biochemical parameters. The leech in the nasopharynx was removed by using forceps. The removed leech was darkcolored and it was approximately $4 \mathrm{~cm}$ in length. The symptoms of the patient completely resolved after the removal of leech and he was discharged the day following the procedure. 


\section{Case 2}

In June 2009, a 12-year-old male was applied to our emergency department with complaints of intermittent epistaxis and asthenia lasting for a month. No significant features were detected in the personal and family history of the patient. The patient was observed to be pale during the physical examination, and the endoscopic examination revealed a dark colored moving foreign body covering the nasopharynx and partly hanging down around the uvula. No significant results were found in the radiological, haematological and biochemical parameters except $10 \mathrm{~g} / \mathrm{dl}$ hemoglobin and $30 \%$ hematocrit. The leech in the nasopharynx was removed by using forceps. The leech was dark colored and $3 \mathrm{~cm}$ in length. The postoperative period was uneventful. Oral iron preparation was initiated postoperatively for six months.

\section{Case 3}

In July 2009, a 70-year-old male was applied to our emergency department with the complaint of intermittent hemoptysis lasting for two weeks. The endoscopic examination revealed a dark colored moving foreign body covering the nasopharynx and partly hanging down to oropharynx. No pathology was detected in the radiological, hematological and biochemical parameters. The leech in the nasopharynx was removed by using forceps. The removed leech was dark colored and approximately $3.5-4 \mathrm{~cm}$ in length. The patient was discharged in the same day after his symptoms resolved.

\section{Discussion}

Leeches are parasitic living beings belonging to the Annelida species of helminths. The parasitic forms of leeches in humans are called hirudiniasis. Leeches live in brooks, rivers and pools. Leech infestations in humans occur mostly by swimming in these brooks and rivers or drinking contaminated waters [4]. As a matter of fact, all three patients included in this study were using well water as drinking water. After the intake of contaminated water, the leech is localized in the upper respiratory system or digestive system. These locations are mostly the nose, nasopharynx, oropharynx, epiglottis, larynx and upper trachea [6].

Leeches attach the mucosa by their large muscular sucker on the tail and bite by their anterior sucker. Their three small jaws bite on the host forming three lines. They secrete an anticoagulant substance containing hirudin, which inhibits the thrombin, factor IXa and other enzymes. These anticoagulants enable the leech to feed on its host freely. If a foreign body in the nasal cavity is a leech, it presents an emergency that requires immediate attention, because after leeches attach themselves to a mucous membrane, they can suck blood up to approximately nine times their own body weight $[2,6]$. They may cause severe anemia, which may require blood transfusion [7, 8]. Cundall et al [9]. reported the death of one of their six cases due to severe anemia. We also observed anemia in one of our cases, but it was not as severe as to threat the patient's life.

Since leech bites are painless due to the local anesthetic substance secreted, symptoms are not recognized until they become apparent [10]. Symptoms depend on the localization place of the leech. If the leech attaches the nasal cavity and nasopharynx, the patient experiences epistaxis, nasal obstruction and a feeling of a foreign body inside the nose. If the leech is found in the oral cavity, the symptoms include hemoptysis and a feeling of a foreign body inside the mouth. The localization of the leech in the larynx causes symptoms like hemoptysis, hoarseness and respiratory distress $[3,8]$. In all our three cases, leeches were localized in the nasopharynx. The two adult cases had the symptom of hemoptysis in addition to epistaxis without any respiratory distress. This situation is probably due to the flow of accumulated blood in the nasopharynx towards the oropharynx resulting in the symptom of hemoptysis.

When the leech is localized in the nose and oral cavity, it is easily diagnosed. On the other hand, its diagnosis may be difficult when the leech is hidden in the nasopharynx [9]. In our first case, the leech which was hidden in the nasopharynx could not be detected by the physician who first examined the patient.

The nasopharynx examination should be performed under general anesthesia in children while possible causes of epistaxis are investigated. When the leech is found attached to the oropharynx, it may be easily removed by using forceps. Necessary caution and attention should be paid while removing the leech from its location; because it has a slippery body surface which can easily be ruptured [11]. In all our three cases, leeches were removed safely in one piece by using forceps without the requirement of anesthesia.

In conclusion, although leeches are rarely observed in the respiratory system, it may occasionally cause life-threatening complications if it is not accurately diagnosed. Therefore, leech infestation should be considered in the presence of unexplained hemoptysis, epistaxis or anemia in leech- endemic areas. Endoscopic evaluation of nasal cavity is mandatory for the definitive diagnosis. Due to contamination risks, people living in rural areas should use natural spring water after boiling and filtering them.

\section{References}

1. Adhikari P. Nasal leech infestation in children: comparison of two different innovative techniques. Int J Pediatr Otorhinolaryngol 2009;73(6):853-855.

2. Kruger C, Malleyeck I, Olsen OH. Aquatic leech infes- 
tation: a rare cause of severe anemia in an adolescent Tanzanian girl. Eur J Pediatr 2004;163(6):297-299.

3. Kaygusuz I, Yalcin S, Keles E. Leeches in the larynx. Eur Arch Otorhinolaryngol 2001;258(9):455-457.

4. Bilgen C, Karci B, Uluoz U. A nasopharyngeal mass: leech in the nasopharynx. Int J Pediatr Otorhinolaryngol 2002;64(1):73-76.

5. WhiteGB, Leeches and leech infestation, in: G.C. Cook (Ed.), Manson's Tropical Diseases, 20th ed., Saunders, London, 1998, pp. 1523-5.

6. Foonant S, Puntasri W, Manorot M, Niwasabutra S. A leech in the nasal cavity: case report. Chiang Mai Med Bull 2006;45:27-30.

7. Montazeri F, Bedayat A, Jamali L, Salehian M, Montazeri G. Leech endoparasitism: report of a case and review of the literature. Eur J Pediatr 2009;168(1):39-42.

8. al-Hadrani A, Debry C, Faucon F, Fingerhut A. Hoarseness due to leech ingestion. J Laryngol Otol 2000;114(2):145-146.

9. Cundall DB, Whitehead SM, Hechtel FO. Severe anemia and death due to the pharyngeal leech Myxobdella africana. Trans R Soc Trop Med Hyg 1986;80(6):940944.

10. Tseng CC, Ho CY. Removal of a nasal leech: a safe and effective method. Otolaryngol Head Neck Surg 2005;132(5):814-815.

11. Ozdek A, Emir H, Kaptan ZK. An Unusual Cause of Adult Dyspnea and Hemoptysis: Leech Infestation of the Larynx. Journal of Ear Nose Throat and Head Neck Surgery 2008;16:138-40. 